\title{
Clinical implication of vascular endothelial growth factor T-460C polymorphism in the risk and progression of prostate cancer
}

\author{
HISAMI FUKUDA ${ }^{1}$, NORIHIKO TSUCHIYA ${ }^{1}$, SHINTARO NARITA ${ }^{1}$, TERUAKI KUMAZAWA ${ }^{1}$, \\ YOHEI HORIKAWA ${ }^{1}$, TAKAMITSU INOUE ${ }^{1}$, MITSURU SAITO ${ }^{1}$, TAKESHI YUASA ${ }^{1}$, \\ SHINOBU MATSUURA ${ }^{1}$, SHIGERU SATOH ${ }^{1}$, OSAMU OGAWA ${ }^{2}$ and TOMONORI HABUCHI ${ }^{1}$ \\ ${ }^{1}$ Department of Urology, Akita University School of Medicine, Akita 010-8543; \\ ${ }^{2}$ Department of Urology, Graduate School of Medicine, Kyoto University, Kyoto 606-8507, Japan
}

Receiced June 5, 2007; Accepted July 16, 2007

\begin{abstract}
Vascular endothelial growth factor (VEGF), one of the most potent angiogenic factors, is suggested to play a crucial role in tumor neovascularization and is associated with tumor progression and metastasis in prostate cancer. This study evaluated the significance of the VEGF T-460C polymorphism in the risk and the progression of prostate cancer. In a case-control experiment, 270 patients with prostate cancer and 252 male controls were investigated to assess the association of the VEGF T-460C polymorphism with the risk of prostate cancer. Prostate-specific antigen (PSA) recurrence in 95 patients who underwent radical prostatectomy and survival in 99 patients with metastases at diagnosis were analyzed to evaluate the influence of the polymorphism in cancer progression. The $C C$ and $T C$ genotypes of the polymorphism were associated with significantly higher rates of PSA recurrence after radical prostatectomy than the $T T$ genotype and were independent predictors of PSA recurrence $(\mathrm{P}=0.011)$ in a multivariate analysis. In contrast, metastatic prostate cancer patients with the $T T$ genotype showed significantly worse survival as compared to the $C C$ and $T C$ genotypes. In a multivariate analysis, the $T T$ genotype was an independent predictor of cancer-specific survival $(\mathrm{P}=0.006)$. The VEGF $T-460 C$ polymorphism may have a substantial impact on both PSA recurrence after radical prostatectomy and survival in advanced prostate cancer. The molecular mechanisms of the polymorphism on the differing status in prostate cancer should be elucidated in further studies.
\end{abstract}

\section{Introduction}

Neovascularization is inevitable in tumor progression and metastasis, since the tumor growth requires the development

Correspondence to: Dr N. Tsuchiya, Department of Urology, Akita University School of Medicine, 1-1-1 Hondo, Akita 0108543, Japan

E-mail: tsuchiya@med.akita-u.ac.jp

Key words: prostate cancer, vascular endothelial growth factor, polymorphism, PSA recurrence, survival and remodeling of the blood vessels to ensure the supply of oxygen and nutrients (1). Vascular endothelial growth factor (VEGF) is a potent angiogenic factor that plays a crucial role in tumor neovascularization through a paracrine mechanism and in tumor growth through an autocrine mechanism $(1,2)$. Many studies have observed that an over-expression of the VEGF in cancer cells is associated with tumor progression and metastasis in various types of cancers (3-5). An increased level of plasma and urinary VEGF in cancer patients is suggested to be a possible diagnostic and prognostic predictor $(6,7)$. In prostate cancer, a higher expression level of VEGF protein in human prostate cancer cells than benign prostate hyperplasia or normal prostate cells was confirmed immunohistochemically $(8,9)$. The immunohistochemical analysis of human prostate specimens and $\mathrm{LNCaP}$ and its metastatic derivatives demonstrated a high VEGF expression in association with cellular dedifferentiation and metastatic potential, respectively $(3,10)$. Meanwhile, an increased microvessel density (MVD) of cancer lesions is shown to be associated with tumor aggressiveness and prognosis (11-13). The MVD of prostate cancer lesions is reported to increase with the progression of the tumor and is a useful marker for predicting pathological stage and malignant potential (13-15).

The VEGF gene, which is mapped on $6 \mathrm{p} 21$, has several important single nucleotide polymorphisms (SNPs) in the promoter, 5'- and 3'-untranslated regions (UTR). Some of these SNPs are reportedly implicated in the risk of various types of cancers such as breast, prostate, bladder cancer and malignant melanoma (16-19) and associations of the SNPs with plasma and urinary VEGF expression levels were demonstrated (20-23). Genetic polymorphisms have also shown to affect the risk of cancer and the survival of cancer patients suggesting that polymorphisms as host genetic factors are partially involved in the progression and response to cancer treatments (24). In previous studies, significant associations were observed between the polymorphisms in the 5'- flanking region of the $V E G F$ promoter, which is highly polymorphic, and various types of cancers and other diseases $(22,25)$. Among the polymorphisms in the promoter region, the $V E G F$ $T-460 C$ polymorphism was reported as a useful genetic marker for prostate cancer and demonstrated the impact on the survival of patients with breast cancer $(16,17)$. 
In this study, we evaluated the significance of the VEGF $T-460 C$ polymorphism in the risk, clinical phenotypes and prognosis of prostate cancer in the Japanese population. The association between the polymorphism and VEGF protein expression and MVD was also examined using prostate specimens obtained at radical prostatectomy.

\section{Materials and methods}

Patients. In a case control experiment, 522 males, comprising of 270 patients with prostate cancer diagnosed at Akita University Hospital, its related community hospitals, or Kyoto University Hospital and 252 male controls attending medical check-ups at community hospitals, were registered. Blood specimens were collected from April 1997 to December 2003 for the prostate cancer patients and from March 1998 to September 2001 for the controls. In a survival analysis of localized prostate cancer, 95 consecutive patients who underwent radical prostatectomy at Akita University Hospital were enrolled in the experiment from July 1989 to December 2003. Patients who underwent neoadjuvant or advent hormone therapy were excluded. In a survival analysis of advanced prostate cancer, 99 patients who had prostate cancer with bone metastasis at diagnosis were enrolled from July 1980 to July 2003. Prostate needle biopsy specimens provided material for pathological diagnosis and metastases were identified using X-ray, CT scan and bone scintigraphy. All the patients had metastatic prostate cancer without any previous treatment for the disease and underwent surgical castration or treatment with LH-RH analogues with or without antiandrogens as the initial hormone therapy after diagnosis. Other optional therapies, such as estrogen, antiandrogen agents, steroids, palliative radiation and combinations of these, were added to or replaced by the preceding therapies when treatment failure was noted. The controls comprised of 252 male volunteers without any apparent voiding symptoms. They were tested for serum total prostate-specific antigen (PSA) levels (the Tandem-R assay) and those with abnormal levels $(\geq 4.0 \mathrm{ng} / \mathrm{ml})$ were omitted from the study. A written informed consent was obtained from all the subjects in both of the studies. The present study was approved by the Institutional Review Board (the Ethics Committee) of the Akita University School of Medicine and the Kyoto University Graduate School of Medicine.

Histological evaluation of specimens obtained by transrectal needle biopsy or transurethral resection of the prostate for voiding symptoms was done for all prostate cancer patients. The clinical or pathological stage of prostate cancer at the time of diagnosis was determined by reviewing the medical records based on the tumor-node-metastasis (TNM) system. Prostate cancer was classified into stage A (T1a-bN0M0), stage B (T1c-2N0M0), stage C (T3-4N0M0) and stage D (T1-4N1M0-1 or T1-4N0-1M1) by the modified WhitmoreJewett system. The final pathological stage was applied for patients who underwent radical prostatectomy and the clinical stage was applied for those who did not undergo radical prostatectomy. Pathological grading was determined according to the General Rule for Clinical and Pathological Studies on Prostate Cancer by the Japanese Urological Association and the Japanese Society of Pathology, which is mainly based on the WHO criteria and the Gleason score. Well, moderately, and poorly differentiated carcinomas generally correspond to Gleason scores of 2-4, 5-7 and 8-10, respectively. In the present study, because the two grading systems were used by local pathologists, the tumor grade system was categorized as follows: low-grade cancer included well-differentiated or Gleason 2-4 carcinomas, intermediate-grade cancer included moderately differentiated or Gleason 5-7 carcinomas and high-grade cancer included poorly differentiated or Gleason 8-10 carcinomas.

Genotyping of VEGF T-460C polymorphism. Polymerase chain reaction-restriction fragment length polymorphism (PCR-RFLP) analysis was used to detect VEGF T-460C polymorphisms. The primer sets were as follows: forward, 5'TGAGTGTGTGCGTGTGGGGTTGAGㅡㅡ -3'; reverse, 5'AGAGCCGTTCCCTCTTTGCTAG -3'. In the forward primer, guanine was substituted for cytosine (underlined) to create a digestion site for HinPl I. PCR was carried out on a $15-\mu 1$ aliquot containing $25 \mathrm{ng}$ of genomic DNA, 12 pmol of each primer, $2.5 \mu 1$ of $10 \mathrm{x}$ buffer solution, $20 \mathrm{nmol} / \mu 1$ each of dATP, dCTP, dGTP and dTTP and 1U of Taq polymerase (Ampli-Taq Gold DNA polymerase, PE Applied Biosystems, Branchburg, NJ, USA). Initial denaturation at $94^{\circ} \mathrm{C}$ for $10 \mathrm{~min}$ was followed by 35 cycles of denaturation at $94^{\circ} \mathrm{C}$ for $30 \mathrm{sec}$, annealing at $60^{\circ} \mathrm{C}$ and extension at $72^{\circ} \mathrm{C}$ for $30 \mathrm{sec}$, with a final extension at $72^{\circ} \mathrm{C}$ for $7 \mathrm{~min}$. The products obtained by overnight digestion at $37^{\circ} \mathrm{C}$ with $\mathrm{HinP} 1 \mathrm{I}$ were electrophoresed on $3.0 \%$ agarose gels. Digestion of the $162 \mathrm{bp} \mathrm{PCR} \mathrm{products}$ resulted in two fragments of 138 and $24 \mathrm{bp}$ where the $\mathrm{C}$ allele was present. Several samples were directly sequenced using PCR primers and a Dye Terminator Sequencing Kit version 1.0 (PE Applied Biosystems) on an ABI prism 310 auto-sequencer to confirm the results of PCR-RFLP for each polymorphism.

Immunohistochemical analysis. Fifty-eight prostate specimens obtained at radical prostatectomy were subjected to immunohistochemical analysis. The pathological $\mathrm{T}$ stage of the cancers was T2 in 29 patients, T3 in 22 and T4 in 7. The Gleason score of the cancers was $<7$ in 11,7 in 27 and $>7$ in 20 specimens. The specimens were fixed in $10 \%$ buffered formalin and embedded in paraffin. A paraffin block containing cancer lesions with representative Gleason scores was selected from each specimen. Tissue sections of $5 \mu \mathrm{m}$ were deparaffinized in xylene and rehydrated through a graded ethanol series. Endogenous peroxidase activity was blocked with $0.3 \%$ hydrogen peroxide for $15 \mathrm{~min}$. To retrieve the antigen, the sections were boiled in $0.01 \mathrm{M}$ citric acid ( $\mathrm{pH}$ 6.0) and non-specific binding was blocked with $5 \%$ goat serum for $10 \mathrm{~min}$. After washing, rabbit anti-VEGF monoclonal antibody (A-20; Santa Cruz, CA, USA) diluted 1:200 was applied and incubated at $4^{\circ} \mathrm{C}$ overnight. After washing in PBS, secondary antibody conjugated with horseradish peroxidase (Histofine Simplestain MAX PO, Nichirei) was applied, followed by incubation at room temperature for $30 \mathrm{~min}$. After washing in PBS again, tissue sections were developed with diamino-benzidine (DAB; Nichirei) and counterstained with hematoxylin. Similarly for CD34 immunostaining, mouse anti-CD34 monoclonal antibody (NU-4A1; Nichirei, 

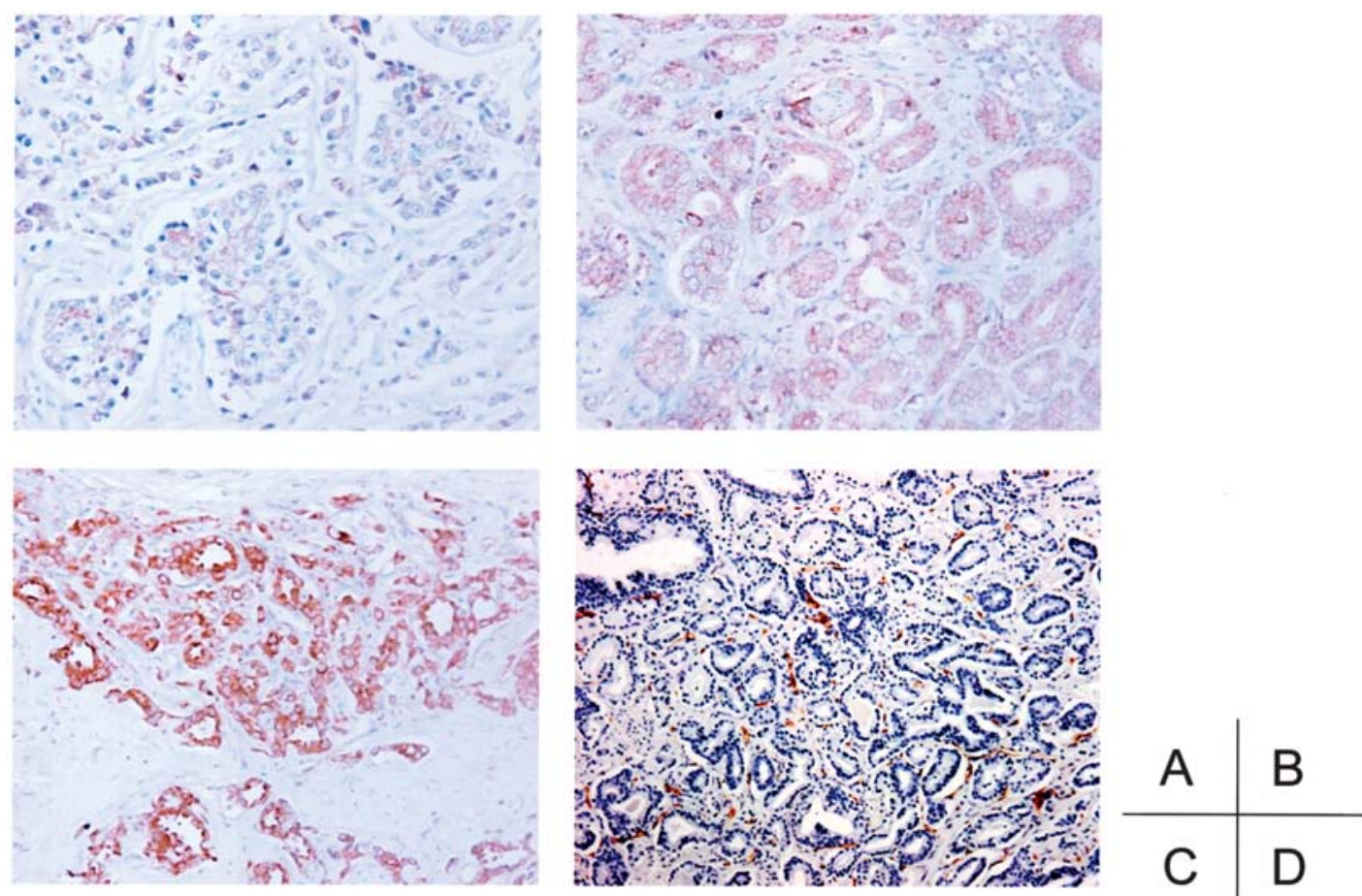

Figure 1. Representative immunohistochemical stainings of vascular endothelial growth factor (VEGF). Prostate cancer lesions with weak, moderate and strong stainings are shown in A, B and C, respectively. A representative immunohistochemical staining of CD34 in a prostate cancer lesion is shown in D.

Tokyo, Japan) diluted 1:100 was used as primary antibody and incubated at $4^{\circ} \mathrm{C}$ overnight.

Assessment of VEGF expression and measurement of microvessel density. The expression of VEGF was assessed using a modified scoring system based on a method previously reported (26). Briefly, VEGF expression was classified into four categories according to the sum of staining intensity ( 0 , negative; 1 , weak; 2 , intermediate; 3 , strong staining) and percentile quadrants of positive cells $(0=0 \%, 1=1-25 \%$, $2=26-50 \%, 3=>50 \%)$. Weak, intermediate, and strong expressions correspond to the sum of the two scores: 0-2, 3-4 and 5-6, respectively (Fig. 1A, B and C).

MVD was assessed by counting the number of microvessels with CD34-positive endothelial cells in four separate high-power fields at $\mathrm{x} 200$ that had the highest vascularization (hot spot) by scanning at $\mathrm{x} 40$ in cancer lesions of each section (Fig. 1D). The mean MVD of the four fields was calculated (27). Each assessment was performed by two independent observers (H.F and N.T.) unaware of clinical information.

Statistical analysis. The age of each group was presented as mean \pm SD and the difference between the groups was analyzed by an unpaired Student's t-test. Hardy-Weinberg equilibrium analyses were performed to compare the observed genotype frequencies with the expected frequencies using the $\chi^{2}$ test. MVDs between groups were compared using ANOVA and the relationship between each genotype and the VEGF expression score determined by IHC was analyzed by the $\chi^{2}$ test. The age-adjusted odds ratio (aOR) and $95 \%$ confidence interval (CI) for the relative risk in each genotype were calculated by multiple logistic regression analysis with the inclusion of a factor of age. To compare PSA recurrence-free survival, patients were dichotomized by median preoperative PSA ( $\geq 11.3$ vs $<11.3 \mathrm{ng} / \mathrm{ml}$ ), pathological $\mathrm{T}$ status (T2 vs T3-4), surgical margin status (positive vs negative), Gleason score ( $\geq 8$ vs $<8$ ), VEGF T-460C genotype (TC or $C C$ vs $T T$ ), VEGF expression score ( $\geq 4$ vs $<4)$ and median MVD $(\geq 27.0$ vs $<27.0)$. PSA recurrence was defined as the persistence of a postoperative serum PSA level $>0.4 \mathrm{ng} / \mathrm{ml}$. Similarly, to compare cancer-specific survival, patients were dichotomized by median age ( $\geq 73$ vs $<73$ years), tumor grade (high vs low/intermediate), pretreatment PSA ( $\geq 186 \mathrm{vs}<186 \mathrm{ng} / \mathrm{ml}$ ), pretreatment hemoglobin ( $<10.5 \mathrm{vs} \geq 10.5 \mathrm{~g} / \mathrm{dl}$ ), alkaline phosphatase (increased vs normal), lactate dehydrogenase (increased vs normal) and VEGF T-460C genotype (TT vs TC or $C C$ ). The survival time was calculated from the date of prostate cancer diagnosis to the day of PSA recurrence, death from prostate cancer, or death from any cause, for PSA recurrence-free, cancer-specific and overall survival, respectively. Survival was evaluated using the Kaplan-Meier method and the statistical difference in survival between groups was evaluated by a log-rank test. The median followup time was computed among all cases. Hazard ratios (HRs) and $95 \%$ CIs for PSA recurrence and cancer death were tested using the Cox proportional hazard regression model. All statistical analyses were performed using SPSS software version 14.0 (SPSS Inc.) and two-sided P-values of $<0.05$ were considered to indicate statistical significance.

\section{Results}

Association between the VEGF polymorphism and the risk of prostate cancer. The mean age of controls and prostate cancer 
Table I. Genotype frequencies of the VEGF T-460C polymorphism and age-adjusted odds ratio against controls.

\begin{tabular}{|c|c|c|c|c|c|c|}
\hline \multirow[b]{2}{*}{ Genotype } & \multicolumn{2}{|c|}{ Prostate cancer } & \multicolumn{2}{|c|}{ Control } & \multirow[b]{2}{*}{$\mathrm{aOR}^{\mathrm{a}}\left(95 \% \mathrm{CI}^{\mathrm{b}}\right)$} & \multirow[b]{2}{*}{ P-value } \\
\hline & $\mathrm{n}$ & $(\%)$ & $\mathrm{n}$ & $(\%)$ & & \\
\hline VEGF T-460C & 270 & & 252 & & & \\
\hline$T T$ & 143 & $(53.0)$ & 132 & $(52.4)$ & ref. & \\
\hline$T C$ & 103 & $(38.1)$ & 97 & $(38.5)$ & $0.976(0.677-1.404)$ & 0.893 \\
\hline$C C$ & 24 & $(8.9)$ & 23 & $(9.1)$ & $0.980(0.719-1.036)$ & 0.900 \\
\hline
\end{tabular}

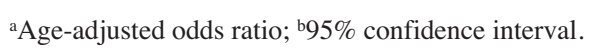

Table II. Genotype frequencies of the VEGF T-460C polymorphism in prostate cancer subgroups and age-adjusted odds ratio against controls.

\begin{tabular}{|c|c|c|c|c|}
\hline \multirow{2}{*}{$\begin{array}{l}V E G F T-460 C \\
\text { Genotype }\end{array}$} & \multicolumn{2}{|c|}{ Stage $^{\mathrm{a}}$} & \multirow{2}{*}{$\mathrm{aOR}^{\mathrm{c}}\left(95 \% \mathrm{CI}^{\mathrm{d}}\right)$} & \multirow{2}{*}{ P-value } \\
\hline & Localized & Metastatic & & \\
\hline$T T$ & $62(54.9)$ & 81 (51.6) & ref & \\
\hline$T C$ & $41(36.3)$ & $62(39.5)$ & $1.170(0.697-1.961)$ & 0.554 \\
\hline$C C$ & $10(8.8)$ & $14(8.9)$ & $1.035(0.668-1.605)$ & 0.876 \\
\hline$T C+C C$ & $51(45.1)$ & $76(48.4)$ & $1.145(0.705-1.862)$ & 0.381 \\
\hline$T T+T C^{5}$ & $103(91.2)$ & $143(91.1)$ & $0.999(0.426-2.342)$ & 0.999 \\
\hline \multirow{3}{*}{$\begin{array}{l}V E G F T-460 C \\
\text { Genotype }\end{array}$} & \multicolumn{2}{|c|}{ Grade $^{\mathrm{b}}$} & \multirow{3}{*}{$\mathrm{aOR}^{\mathrm{c}}\left(95 \% \mathrm{CI}^{\mathrm{d}}\right)$} & \multirow{3}{*}{ P-value } \\
\hline & \multirow{2}{*}{\multicolumn{2}{|c|}{ Low+Intermidiate }} & & \\
\hline & & & & \\
\hline$T T$ & $87(53.4)$ & $55(52.4)$ & ref & \\
\hline$T C$ & $63(38.6)$ & $39(37.1)$ & $0.991(0.585-1.676)$ & 0.972 \\
\hline$C C$ & $13(8.0)$ & $11(10.5)$ & $1.156(0.748-1.787)$ & 0.514 \\
\hline$T C+C C$ & $76(46.6)$ & $50(47.6)$ & $1.048(0.640-1.716)$ & 0.853 \\
\hline$T T+T C^{e}$ & $150(92.0)$ & $94(89.5)$ & $0.750(0.321-1.748)$ & 0.505 \\
\hline
\end{tabular}

${ }^{a}$ Localized, stage A-C; metastatic, stage D; b ${ }^{2}$ ow, well-differenciated or Gleason score 2-4; intermediate, moderately differenciated or Gleason score 5-7; High, poorly differenciated or Gleason score $8-10 ;{ }^{c}$ age-adjusted odds ratio; ${ }^{\mathrm{d}} 95 \%$ confidence interval, ${ }^{\mathrm{e}}$ vs CC genotype.

patients were $71.2 \pm 8.0$ and $71.7 \pm 7.9$ years, respectively. There was no significant difference in the mean age between the groups $(\mathrm{P}=0.838)$. Tumors were classified as stage $\mathrm{A}, \mathrm{B}, \mathrm{C}$ and $\mathrm{D}$ such as $26,88,56$ and 100 patients, respectively. Low, intermediate and high-grade tumors were observed in 42, 121 and 105 patients, respectively and the pathological grade was unknown in two patients due to inadequate records of local pathologists. The observed genotype frequency of the polymorphism did not differ from the expected frequency according to the Hardy-Weinberg equilibrium in the control group (data not shown).

The genotype distribution of the VEGF T-460C polymorphism is summarized in Table I. The frequencies of the $T T, T C$ and $C C$ genotypes in the control group were 52.4, 38.5 and $9.1 \%$, respectively. The frequencies of these genotypes in the prostate cancer group were 53.0, 38.1 and $8.9 \%$, respectively. There was no significant difference in the genotype distribution between the two groups. Age-adjusted logistic regression analysis showed no association between the genotype of the polymorphism and the risk of prostate cancer. When the patients were classified according to tumor stage and grade, there were no significant differences in genotype distribution either between the high-grade cancer and the low-grade cancer groups, or between stage A + B + C (nonmetastatic) patients and stage D (metastatic) patients (Table II). For the age at the onset of prostate cancer, the subjects were divided into two groups using the median age at diagnosis in prostate cancer patients ( 72 years). There were no significant differences in the three genotype frequencies between patients aged 72 years or over and those under 72 and in the mean age of diagnosis of prostate cancer between the three genotype groups (data not shown).

Association of the VEGF polymorphism with expression of $V E G F$ and microvessel density. There was no association between the VEGF T-460C genotypes and VEGF protein expression score $(\mathrm{P}=0.199)$. When the same analysis was performed in each subgroup and divided according to pathological $\mathrm{T}$ stage (T2 or T3-4) or Gleason score ( $\leq 7$ or $>7$ ), no association between the genotypes and VEGF expression level was observed (Table III). Mean MVD in the prostate cancer lesions reported no association with VEGF T- 
Table III. Association of genotypes of the VEGF T-460C with VEGF expression level and microvessel density.

\begin{tabular}{|c|c|c|c|c|c|c|}
\hline \multirow{2}{*}{$\begin{array}{l}\text { VEGF T-460C } \\
\text { Genotype }\end{array}$} & \multicolumn{3}{|c|}{ VEGF expression ${ }^{\mathrm{a}}$ according to $\mathrm{IHC}^{\mathrm{b}}$} & \multirow{2}{*}{ P-value ${ }^{c}$} & \multirow{2}{*}{$\begin{array}{l}\text { Microvessel } \\
\text { density }^{\mathrm{d}}\end{array}$} & \multirow{2}{*}{ P-value ${ }^{e}$} \\
\hline & weak & intermediate & strong & & & \\
\hline$T T$ & 7 & 12 & 11 & & $29.6 \pm 14.4$ & \\
\hline$T C$ & 7 & 6 & 12 & & $28.6 \pm 16.3$ & \\
\hline$C C$ & 0 & 3 & 0 & 0.199 & $34.3 \pm 24.1$ & 0.833 \\
\hline
\end{tabular}

${ }^{a}$ Weak, intermediate and strong correspond to expression score 0-2, 3-4 and 5-7, respectively; ${ }^{b}$ Immunohistochemistry; ${ }^{c} \chi^{2}$-square test; ${ }^{d}$ Mean \pm SD, ${ }^{\mathrm{e}}$ ANOVA test.

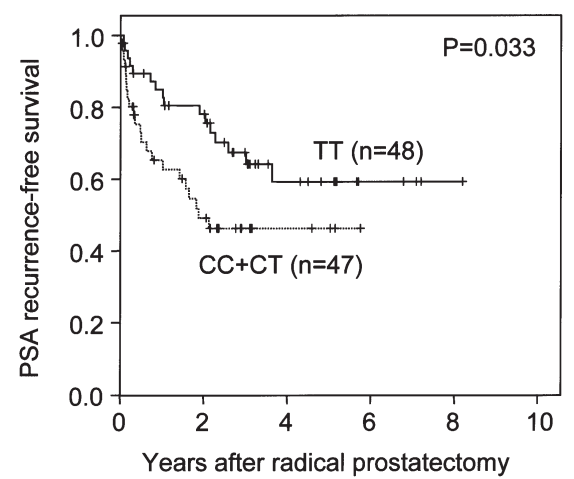

Figure 2. Kaplan-Meier curves of PSA recurrence-free survival stratified by genotype of the VEGF $T-460 C$ polymorphism in prostate cancer patients who underwent radical prostatectomy.

460C genotypes $(P=0.833)$. In each subgroup divided according to pathological $\mathrm{T}$ stage (T2 or T3-4) or Gleason score $(\leq 7$ or $>7)$, no statistical difference in the mean MVD was observed between the genotypes (Table III).

The association between the VEGF polymorphism and progression after radical prostatectomy. The mean age $( \pm \mathrm{SD})$ of the 95 patients who underwent radical prostatectomy was $70.2 \pm 5.1$ years (range, 55-83; median, 71 years). The mean follow-up period was $26.3 \pm 22.8$ months (range, 1-98; median, 25 months). The mean preoperative serum PSA was $17.0 \pm 14.9 \mathrm{ng} / \mathrm{ml}$ (range 2.8-65.0 ng/ml). The distribution of clinical stage was T1, T2, and T3 in 45 (47.4\%), 36 (37.9\%) and $14(14.7 \%)$, respectively. The distribution of pathological stage was T2, T3 and T4 in 51 (53.7\%), 41 $(43.2 \%)$, and $3(4.2 \%)$, respectively and positive surgical margin was observed in $45(47.4 \%)$. Gleason sum score of $<7,7$ and $>7$ were present in $18(19.0 \%), 44(46.3 \%)$ and 33 (34.7\%, respectively. The 3- and 5-year PSA recurrence-free survival rates were $56.8 \%$ and $51.6 \%$, respectively, with a median survival time of 58.1 months. Kaplan-Meier survival curves stratified by $V E G F$ genotype showed that patients with the $T C$ or $C C$ genotype had a significantly higher rate of PSA recurrence compared with the $T T$ genotype $(\mathrm{P}=0.033$, log-rank test, Fig. 2). The VEGF expression score $(\mathrm{P}=0.929)$ and MVD $(\mathrm{P}=0.303)$ were not influential factors in the survival. Univariate analysis of the PSA recurrence-free survival stratified by dichotomized groups in each factor showed that $\mathrm{PSA} \geq 11.3(\mathrm{P}=0.003)$, pathological $\mathrm{T}$ status $\geq \mathrm{T} 3$
$(\mathrm{P}<0.001)$, positive surgical margin $(\mathrm{P}=0.011)$, Gleason sum score $\geq 8(\mathrm{P}<0.001)$ and the $T C$ or $C C$ genotype $(\mathrm{P}=0.037)$ were associated with poor survival (Table IV). In multivariate analysis, higher pathological T status (T3-4), higher Gleason sum score $(\geq 8)$ and the presence of the $T C$ or $C C$ genotype were independent risk factors predicting PSA recurrence after radical prostatectomy, with HRs of 2.789 (95\% CI, 1.292-6.022; $\mathrm{P}=0.009), 3.274$ (95\% CI, 1.641-6.534; $\mathrm{P}=0.001)$ and 2.463 (95\% CI, 1.233-4.926; $\mathrm{P}=0.011)$, respectively (Table IV).

Association between the VEGF polymorphism and survival of metastatic prostate cancer. The mean age $( \pm$ SD) of the 99 patients with bone metastasis at diagnosis was $72.6 \pm 8.5$ years (range, 53-89; median, 73 years). The mean follow-up period was 53.3 \pm 38.9 months (range, 2-184; median, 45 months). The 5- and 10-year overall survival rates were 52.2 and $25.8 \%$, respectively, with a median survival time of 64.8 months. Survival was compared between the two groups divided according to the genotype of the $V E G F$ polymorphisms, i.e., patients with the $T T$ genotype $(\mathrm{n}=52)$ and with the $T C$ or $C C$ genotype $(\mathrm{n}=47)$. The $T T$ genotype of the VEGF T-460C polymorphism was associated with significantly worse cancer-specific and overall survival compared with the $T C$ or $C C$ genotype $(\mathrm{P}=0.036$ and $\mathrm{P}=0.030$, respectively; Fig. $3 \mathrm{~A}$ and $\mathrm{B})$. The 5-year overall survival rates were 45.3 and $60.2 \%$ and the 10-year overall survival rates were 7.4 and $40.6 \%$ for patients with the $T T$ genotype and the $T C$ or $C C$ genotype, respectively. The median cancer-specific survival rates of patients with the $T T$ and the $T C$ or $C C$ genotype were 46.9 and 81.6 months, respectively and the median overall survival rates of patients with the $T T$ and the $T C$ or $C C$ genotype were 46.9 and 76.9 months, respectively. In a univariate analysis, tumor grade $(\mathrm{P}<0.001)$, pretreatment PSA $(\mathrm{P}=0.025)$, hemoglobin $(\mathrm{P}=0.009)$, alkaline phosphatase $(\mathrm{P}<0.001)$ and VEGF polymorphism $(\mathrm{P}=0.025)$ were significantly associated with cancer-specific survival. A multivariate analysis revealed that the VEGF polymorphism $(\mathrm{P}=0.006)$ and tumor grade $(\mathrm{P}=0.039)$, hemoglobin $(\mathrm{P}=0.007)$ and alkaline phosphatase $(\mathrm{P}=0.009)$ were independent predictors of cancer-specific survival (Table V).

\section{Discussion}

Most of the VEGF polymorphisms previously examined are located in the 5'-flanking region and some are considered to affect the transcription activity of the gene, resulting in inter- 
Table IV. Cox proportional hazard regression analysis of predicting factors for PSA progression-free survival after radical prostatectomy.

\begin{tabular}{|c|c|c|c|c|}
\hline \multirow{2}{*}{ Variable } & \multirow{2}{*}{ Category for statistical analysis } & \multicolumn{3}{|c|}{ PSA progression-freec survival } \\
\hline & & $\mathrm{HR}^{\mathrm{a}}$ & $95 \% \mathrm{CI}^{\mathrm{b}}$ & P-value \\
\hline \multicolumn{5}{|l|}{ Univariate analysis } \\
\hline Preoperative PSA & $\geq 11.3 \mathrm{vs}<11.3(\mathrm{ng} / \mathrm{ml})$ & 2.769 & $1.419-5.405$ & 0.003 \\
\hline Pathological T status & $\mathrm{T} 3-4$ vs T2 & 3.683 & $1.886-7.193$ & $<0.001$ \\
\hline Surgical margin status & Positive vs Negative & 2.373 & $1.217-4.626$ & 0.011 \\
\hline Gleason score & $\geq 8$ vs $<8$ & 3.177 & $1.680-6.009$ & $<0.001$ \\
\hline VEGF T-460C polymorphism & $T C / C C$ vs $T T$ & 1.996 & $1.042-3.817$ & 0.037 \\
\hline VEGF expression score & $\geq 4$ vs $<4$ & 1.040 & $0.436-2.480$ & 0.929 \\
\hline Microvascular density & $\geq 27.0$ vs $<27.0$ & 1.459 & $0.708-3.006$ & 0.303 \\
\hline \multicolumn{5}{|l|}{ Multivariate analysis } \\
\hline Preoperative PSA & $\geq 11.3 \mathrm{vs}<11.3(\mathrm{ng} / \mathrm{ml})$ & 1.841 & $0.884-3.834$ & 0.103 \\
\hline Pathological T status & $\mathrm{T} 3-4$ vs T2 & 2.789 & $1.292-6.022$ & 0.009 \\
\hline Surgical margin status & Positive vs Negative & 1.831 & $0.881-3.802$ & 0.105 \\
\hline Gleason score & $\geq 8$ vs $<8$ & 3.274 & $1.641-6.534$ & 0.001 \\
\hline$V E G F T-460 C$ polymorphism & $T C / C C$ vs $T T$ & 2.463 & $1.233-4.926$ & 0.011 \\
\hline
\end{tabular}

${ }^{\text {a} H a z a r d ~ r a t i o ; ~}{ }^{\mathrm{b}} 95 \%$ confidence interval.

A

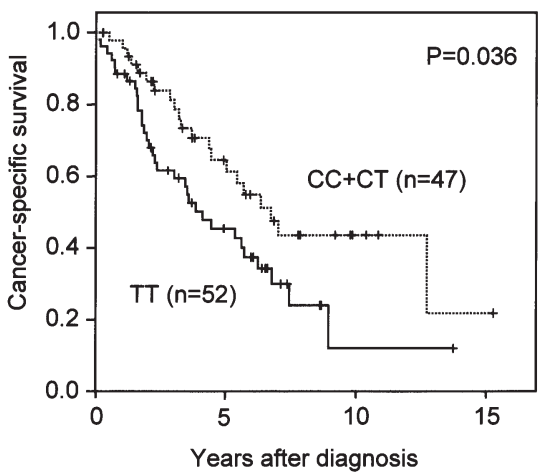

B

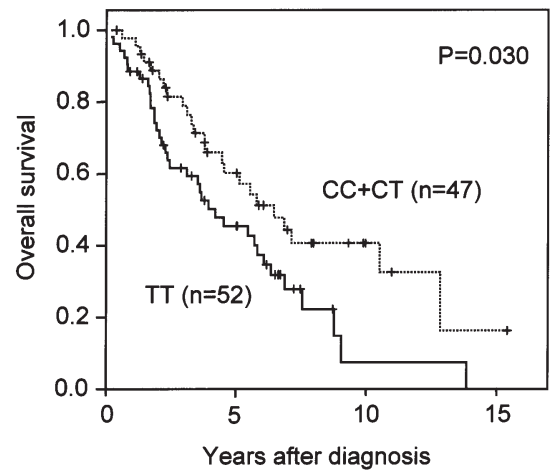

Figure 3. Kaplan-Meier curves of cancer-specific (A) and overall (B) survival stratified by genotype of the VEGF T-460C polymorphism in prostate cancer patients with bone metastasis at diagnosis.

individual variations in the concentration of tissue and circulating VEGF protein $(22,25)$. For example, the $C, G, C$, $C$ and $G$ alleles of the $C-2578 A, G-1154 A, G-634 C, T-460 C$ and $G-405 C$ polymorphisms, respectively, are related to higher VEGF expression levels and men with the T allele of C936T reportedly have lower plasma VEGF levels (20-23). The association between the $C$ allele of the $C-460 T$ polymorphism and the risk of disease was demonstrated for cancers of the breast, prostate and oral cavity, psoriasis, end-stage kidney disease and proliferative diabetic retinopathy (16,17,28-31). Conversely, a series of studies from Taiwan showed an association between the $T T$ homozygote of the $C-460 T$ polymorphism and risk of prostate cancer, oral cancer and endometriosis $(17,28,32)$. With regard to the controversial results, since none of the genotype frequencies of the control groups in the studies were in Hardy-Weinberg equilibrium $(17,28,32)$, these results must be attributed to problems of experimental technique or sampling bias of the control subjects.

Several studies have reported that the presence of the $C$ allele or the $C C$ genotype of the VEGF $C-460 T$ polymorphism is a risk factor for disease progression in chronic renal disease and for poor survival in breast cancer $(16,30)$. The present study demonstrated that $\mathrm{PSA}$ recurrence after radical prostatectomy was significantly associated with the $C$ allele of the polymorphism. Since it is known that VEGF is involved in tumor neovascularization through a paracrine mechanism and tumor growth through an autocrine mechanism $(1,2)$, higher VEGF levels in the tumor microenvironment possibly induce more rapid progression and robust survival of residual tumor and may develop metastasis or local recurrence under circumstances of activated tumor growth and abundant tumor vessels. Therefore, our finding that the $C$ allele is associated with a higher probability of PSA recurrence after radical 
Table V. Cox proportional hazard regression analysis of predicting factors for Cancer-specific survival in prostate cancer patients with bone metastasis at diagnosis.

\begin{tabular}{|c|c|c|c|c|}
\hline \multirow{2}{*}{ Variable } & \multirow{2}{*}{ Category for statistical analysis } & \multicolumn{3}{|c|}{ Cancer-specific survival } \\
\hline & & $\mathrm{HR}^{\mathrm{a}}$ & $95 \% \mathrm{CI}^{\mathrm{b}}$ & P-value \\
\hline \multicolumn{5}{|l|}{ Univariate analysis } \\
\hline Age & $\geq 73$ vs $<73$ (yrs) & 1.252 & $0.726-2.159$ & 0.420 \\
\hline Tumor grade & nHigh vs Low/Intermediate ${ }^{c}$ & 3.138 & $1.644-5.918$ & $<0.001$ \\
\hline PSA & $\geq 186 \mathrm{vs}<186(\mathrm{ng} / \mathrm{ml})$ & 1.933 & $1.087-3.438$ & 0.025 \\
\hline Hemoglobin & $<11.5$ vs $\geq 11.5(\mathrm{~g} / \mathrm{dl})$ & 2.463 & $1.256-4.831$ & 0.009 \\
\hline Alkaline phosphatase & Increased vs Normal & 3.922 & 2.049-7.519 & $<0.001$ \\
\hline Lactate dehydrogenase & Increased vs Normal & 1.267 & $0.666-2.410$ & 0.471 \\
\hline VEGF T-460C polymorphism & $T T$ vs $T C / C C$ & 1.852 & $1.079-3.185$ & 0.025 \\
\hline \multicolumn{5}{|l|}{ Multivariate analysis } \\
\hline Tumor grade & High vs Low/Intermediate ${ }^{c}$ & 2.354 & $1.043-5.309$ & 0.039 \\
\hline PSA & $\geq 186$ vs $<186(\mathrm{ng} / \mathrm{ml})$ & 1.184 & $0.805-4.092$ & 1.151 \\
\hline Hemoglobin & $<11.5 \mathrm{vs} \geq 11.5(\mathrm{~g} / \mathrm{dl})$ & 2.882 & $1.342-6.173$ & 0.007 \\
\hline Alkaline phosphatase & Increased vs Normal & 3.175 & $1.330-7.576$ & 0.009 \\
\hline VEGF T-460C polymorphism & $T T$ vs $T C / C C$ & 2.976 & $1.364-6.494$ & 0.006 \\
\hline
\end{tabular}

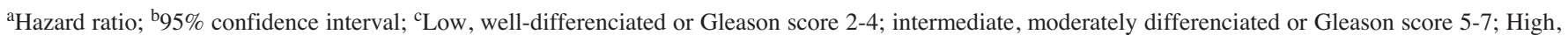
poorly differenciated or Gleason score 8-10.

prostatectomy is thought to be in line with previous studies that identified the $C$ allele of the polymorphism as a risk allele for disease.

In contrast to previous studies, the present study report that patients with the $T T$ genotype, which is considered to be associated with the lower expression of VEGF, showed a worse survival in patients with metastasis at diagnosis. Moreover, in addition to other clinical factors that have been reported to predict survival, the $T T$ genotype was an independent predictor. Although we do not know the exact reason for the contradictory results, a similar finding is observed in predicting survival in prostate cancer by pretreatment serum testosterone level. Lower pretreatment serum testosterone levels have been reported to be associated with a lower response to endocrine therapy, leading to worse survival in patients with metastatic prostate cancer (33). Since androgen ablation therapy is a standard and first-line treatment for metastatic prostate cancer, endocrine therapies were administered to most of the patients in a standardized fashion. It is known that testosterone induces VEGF synthesis and prostate cancer cell proliferation and expression of VEGF in prostate cancer is significantly reduced by endocrine therapies, suggesting that advanced prostate cancer with lower VEGF expression possibly shows less response to the endocrine therapies than cancer with higher VEGF expression $(34,35)$. The higher VEGF levels induced by the $C$ allele of the $C-460 T$ polymorphism may positively influence local recurrence or early micro-metastases by facilitating neovascularization, while metastatic prostate cancers with lower VEGF levels, partially detracted by the T allele, may have a poor response to the endocrine therapy. Further analyses with a large number of patients and various clinical factors are needed to validate our preliminary findings and speculations.

In this study, we failed to show an association between the VEGF C-460T polymorphism and risk of prostate cancer and clinical phenotype at diagnosis. Prostate cancer is a slowgrowing cancer with a long period of time between initiation and clinically significant cancer, suggesting that progression rather than initiation is the rate-limiting factor for the diagnosis of clinical cancer. Various factors, such as angiogenic factors responsible for the tumor microenvironment, are involved in the clinical elicitation of prostate cancer. These factors are known to show inter-individual variation, partially explained by genetic polymorphisms and may act in a coordinated manner with the VEGF polymorphisms on cancer progression. In addition, since there are several significant polymorphisms besides $C-460 T$, which may have an association with the risk of prostate cancer independently or cooperatively. Haplotype analyses among those polymorphisms are needed to further understand the significance of the VEGF polymorphisms.

The significant association of VEGF protein expression and MVD in prostatectomy specimens with tumor stage, Gleason score and progression after surgery are reported in several studies $(36,37)$, however, conflicting results regarding MVD have also been published $(38,39)$. This study, which is the first attempt to assess the influence of the $V E G F$ polymorphism on VEGF expression and MVD in human prostate cancer specimens, demonstrated no significant association. In the previous studies, biological functions of genetic polymorphisms were investigated using a technique in which cultured cells are transfected with plasmids containing polymorphic sequences, or using healthy individuals to measure the serum concentration or activity of products that are expected to be influenced by the polymorphisms $(22,40)$. Since various clinical or pathological factors such as tumor extension and grade possibly have a strong effect on VEGF expression and MVD in radical prostatectomy specimens, it may be difficult to evaluate the effect of the VEGF polymorphism in the tissue section of prostatectomy specimens. The present study also report a lack of association of VEGF 
expression and MVD with PSA recurrence. These results may be partially attributed to the small number of subjects analyzed and the evaluation methods used. VEGF may play an important role in the tumor microenvironment that facilitates tumor recurrence in other sites in the prostate gland. Furthermore, scoring VEGF expression and measuring MVD using immunostaining are labor-intensive and less objective and there are no definite methods for evaluating multifocal prostate cancer lesions, suggesting that it may be difficult to apply these tests in the clinical setting.

In conclusion, the VEGF T-460C polymorphism may be associated with both PSA recurrence after radical prostatectomy and survival in advanced prostate cancer, though the polymorphism did not appear to be involved in the development of prostate cancer. The molecular mechanisms and clinical implications of the contradictory effects of the polymorphism on disease of differing status (e.g. localized vs metastatic) in prostate cancer should be elucidated in further studies.

\section{Acknowledgements}

We are grateful to Ms. Y. Mitobe and Ms. T. Shibata (Department of Urology, Akita University School of Medicine, Japan) for their excellent technical assistance.

\section{References}

1. Ferrara N, Gerber H-P and LeCouter J: The biology of VEGF and its receptors. Nat Med 9: 669-676, 2003.

2. Bachelder RE, Crago A, Chung J, Wendt MA, Shaw LM, Robinson G and Mercurio AM: Vascular endothelial growth factor is an autocrine survival factor for neuropilin-expressing breast carcinoma cells. Cancer Res 61: 5736-5740, 2001.

3. Harper ME, Glynne-Jones E, Goddard L, Thurston VJ and Griffiths K: Vascular endothelial growth factor (VEGF) expression in prostatic tumours and its relationship to neuroendocrine cells. Br J Cancer 74: 910-916, 1996.

4. Takahashi A, Sasaki H, Kim SJ, Tobisu K, Kakizoe T, Tsukamoto T, Kumamoto Y, Sugimura T and Terada M: Markedly increased amounts of messenger RNAs for vascular endothelial growth factor and placenta growth factor in renal cell carcinoma associated with angiogenesis. Cancer Res 54: 4233-4237, 1994.

5. Toi M, Hoshina S, Takayanagi T and Tominaga T: Association of vascular endothelial growth factor expression with tumor angiogenesis and with early relapse in primary breast cancer. Jpn J Cancer Res 85: 1045-1049, 1994.

6. Sato K, Tsuchiya N, Sasaki R, Shimoda N, Satoh S, Ogawa O and Kato T: Increased serum levels of vascular endothelial growth factor in patients with renal cell carcinoma. Jpn J Cancer Res 90: 874-879, 1999.

7. Crew JP, O'Brien T, Bicknell R, Fuggle S, Cranston D and Harris AL: Urinary vascular endothelial growth factor and its correlation with bladder cancer recurrence rates. J Urol 161: 799-804, 1999.

8. Ferrer FA, Miller LJ, Andrawis RI, Kurtzman SH, Albertsen PC, Laudone VP and Kreutzer DL: Vascular endothelial growth factor (VEGF) expression in human prostate cancer: in situ and in vitro expression of VEGF by human prostate cancer cells. J Urol 157: 2329-2333, 1997.

9. Ferrer FA, Miller LJ, Andrawis RI, Kurtzman SH, Albertsen PC, Laudone VP and Kreutzer DL: Angiogenesis and prostate cancer: in vivo and in vitro expression of angiogenesis factors by prostate cancer cells. Urology 51: 161-167, 1998.

10. Balbay MD, Pettaway CA, Kuniyasu H, Inoue K, Ramirez E, Li E, Fidler IJ and Dinney CP: Highly metastatic human prostate cancer growing within the prostate of athymic mice overexpresses vascular endothelial growth factor. Clin Cancer Res 5: 783-789, 1999.
11. Bochner BH, Cote RJ, Weidner N, Groshen S, Chen SC, Skinner DG and Nichols PW: Angiogenesis in bladder cancer: relationship between microvessel density and tumor prognosis. $\mathrm{J}$ Natl Cancer Inst 87: 1603-1612, 1995.

12. Weidner N, Folkman J, Pozza F, Bevilacqua P, Allred EN, Moore DH, Meli S and Gasparini G: Tumor angiogenesis: a new significant and independent prognostic indicator in early-stage breast carcinoma. J Natl Cancer Inst 84: 1875-1887, 1992.

13. Brawer MK: Quantitative microvessel density. A staging and prognostic marker for human prostatic carcinoma. Cancer 78 : 345-349, 1996.

14. Brawer MK, Deering RE, Brown M, Preston SD and Bigler SA: Predictors of pathologic stage in prostatic carcinoma. The role of neovascularity. Cancer 73: 678-687, 1994.

15. Sakr WA and Grignon DJ: Prostate cancer: indicators of aggressiveness. Eur Urol 32: 15-23, 1997.

16. Lu H, Shu XO, Cui Y, Kataoka N, Wen W, Cai Q, Ruan ZX, Gao YT and Zheng W: Association of genetic polymorphisms in the VEGF gene with breast cancer survival. Cancer Res 65: 5015-5019, 2005

17. Lin CC, Wu HC, Tsai FJ, Chen HY and Chen WC: Vascular endothelial growth factor gene-460 $\mathrm{C} / \mathrm{T}$ polymorphism is a biomarker for prostate cancer. Urology 62: 374-377, 2003.

18. Kim EJ, Jeong P, Quan C, Kim J, Bae SC, Yoon SJ, Kang JW, Lee SC, Jun Wee J and Kim WJ: Genotypes of TNF-alpha, VEGF, hOGG1, GSTM1, and GSTT1: useful determinants for clinical outcome of bladder cancer. Urology 65: 70-75, 2005.

19. Howell WM, Bateman AC, Turner SJ, Collins A and Theaker JM: Influence of vascular endothelial growth factor single nucleotide polymorphisms on tumour development in cutaneous malignant melanoma. Genes Immun 3: 229-232, 2002.

20. Shahbazi M, Fryer AA, Pravica V, Brogan IJ, Ramsay HM, Hutchinson IV and Harden PN: Vascular endothelial growth factor gene polymorphisms are associated with acute renal allograft rejection. J Am Soc Nephrol 13: 260-264, 2002.

21. Awata T, Inoue K, Kurihara S, Ohkubo T, Watanabe M, Inukai K, Inoue I and Katayama S: A common polymorphism in the 5'untranslated region of the VEGF gene is associated with diabetic retinopathy in type 2 diabetes. Diabetes 51: 1635-1639, 2002.

22. Stevens A, Soden J, Brenchley PE, Ralph S and Ray DW: Haplotype analysis of the polymorphic human vascular endothelial growth factor gene promoter. Cancer Res 63: 812-816, 2003.

23. Renner W, Kotschan S, Hoffmann C, Obermayer-Pietsch B and Pilger E: A common $936 \mathrm{C} / \mathrm{T}$ mutation in the gene for vascular endothelial growth factor is associated with vascular endothelial growth factor plasma levels. J Vasc Res 37: 443-448, 2000.

24. Tsuchiya N, Wang L, Suzuki H, Segawa T, Fukuda H, Narita S, Shimbo M, Kamoto T, Mitsumori K, Ichikawa T, Ogawa O, Nakamura A and Habuchi T: Impact of IGF-I and CYP19 gene polymorphisms on the survival of patients with metastatic prostate cancer. J Clin Oncol 24: 1982-1989, 2006.

25. Jin Q, Hemminki K, Enquist K, Lenner P, Grzybowska E, Klaes R, Henriksson R, Chen B, Pamula J, Pekala W, Zientek H, Rogozinska-Szczepka J, Utracka-Hutka B, Hallmans G and Forsti A: Vascular endothelial growth factor polymorphisms in relation to breast cancer development and prognosis. Clin Cancer Res 11: 3647-3653, 2005

26. Karavasilis V, Malamou-Mitsi V, Briasoulis E, Tsanou E, Kitsou E, Kalofonos H, Fountzilas G, Fotsis T and Pavlidis N: Angiogenesis in cancer of unknown primary: clinicopathological study of CD34, VEGF and TSP-1. BMC Cancer 5: 25, 2005.

27. Weidner N, Carroll PR, Flax J, Blumenfeld W and Folkman J: Tumor angiogenesis correlates with metastasis in invasive prostate carcinoma. Am J Pathol 143: 401-409, 1993.

28. Ku KT, Wan L, Peng HC, Tsai MH, Tsai CH and Tsai FJ: Vascular endothelial growth factor gene-460 C/T polymorphism is a biomarker for oral cancer. Oral Oncol 41: 497-502, 2005.

29. Young HS, Summers AM, Read IR, Fairhurst DA, Plant DJ, Campalani E, Smith CH, Barker JN, Detmar MJ, Brenchley PE and Griffiths CE: Interaction between genetic control of vascular endothelial growth factor production and retinoid responsiveness in psoriasis. J Invest Dermatol 126: 453-459, 2006.

30. Summers AM, Coupes BM, Brennan MF, Ralph SA, Short CD and Brenchley PE: VEGF -460 genotype plays an important role in progression to chronic kidney disease stage 5. Nephrol Dial Transplant 20: 2427-2432, 2005.

31. Ray D, Mishra M, Ralph S, Read I, Davies R and Brenchley P: Association of the VEGF gene with proliferative diabetic retinopathy but not proteinuria in diabetes. Diabetes 53: 861-864, 2004. 
32. Hsieh YY, Chang CC, Tsai FJ, Yeh LS, Lin CC and Peng CT: T allele for VEGF gene-460 polymorphism at the 5'-untranslated region: association with a higher susceptibility to endometriosis. J Reprod Med 49: 468-472, 2004.

33. Imamoto $T$, Suzuki H, Akakura K, Komiya A, Nakamachi $H$, Ichikawa T, Igarashi T and Ito $\mathrm{H}$ : Pretreatment serum level of testosterone as a prognostic factor in Japanese men with hormonally treated stage D2 prostate cancer. Endocr J 48: 573-578, 2001.

34. Haggstrom S, Lissbrant IF, Bergh A and Damber JE: Testosterone induces vascular endothelial growth factor synthesis in the ventral prostate in castrated rats. J Urol 161: 1620-1625, 1999.

35. Mazzucchelli R, Montironi R, Santinelli A, Lucarini G, Pugnaloni A and Biagini G: Vascular endothelial growth factor expression and capillary architecture in high-grade PIN and prostate cancer in untreated and androgen-ablated patients. Prostate 45: 72-79, 2000.

36. Kuniyasu H, Troncoso P, Johnston D, Bucana CD, Tahara E, Fidler IJ and Pettaway CA: Relative expression of type IV collagenase, E-cadherin, and vascular endothelial growth factor/vascular permeability factor in prostatectomy specimens distinguishes organ-confined from pathologically advanced prostate cancers. Clin Cancer Res 6: 2295-2308, 2000.
37. Strohmeyer D, Rossing C, Strauss F, Bauerfeind A, Kaufmann O and Loening S: Tumor angiogenesis is associated with progression after radical prostatectomy in $\mathrm{pT} 2 / \mathrm{pT} 3$ prostate cancer. Prostate 42: 26-33, 2000

38. Rubin MA, Buyyounouski M, Bagiella E, Sharir S, Neugut A, Benson M, de la Taille A, Katz AE, Olsson CA and Ennis RD: Microvessel density in prostate cancer: lack of correlation with tumor grade, pathologic stage, and clinical outcome. Urology 53: 542-547, 1999.

39. Silberman MA, Partin AW, Veltri RW and Epstein JI: Tumor angiogenesis correlates with progression after radical prostatectomy but not with pathologic stage in Gleason sum 5 to 7 adenocarcinoma of the prostate. Cancer 79: 772-779, 1997.

40. Rietveld I, Janssen JA, van Rossum EF, Houwing-Duistermaat JJ, Rivadeneira F, Hofman A, Pols HA, van Duijn CM and Lamberts SW: A polymorphic CA repeat in the IGF-I gene is associated with gender-specific differences in body height, but has no effect on the secular trend in body height. Clin Endocrinol 61: 195-203, 2004. 